\title{
Role of BiPAP applied through endotracheal tube in unconscious patients suffering from acute exacerbation of COPD: a pilot study
}

This article was published in the following Dove Press journal:

International Journal of COPD

10 May 2012

Number of times this article has been viewed

\author{
Jagdish Rawat' \\ Girish Sindhwani' \\ Debasis Biswas ${ }^{2}$ \\ Ruchi Dua' \\ 'Department of Pulmonary Medicine, \\ ${ }^{2}$ Department of Microbiology, \\ Himalayan Institute of Medical \\ Sciences, Swami Ram Nagar, Jolly \\ Grant, Dehradun, Uttarakhand, India
}

Correspondence: Jagdish Rawat Department of Pulmonary Medicine, Himalayan Institute of Medical Sciences, HIHT University, Swami Ram Nagar, Jolly Grant, Dehradun 248I40, India Tel +9 I I35 247| 362

Fax +9। I35 247/3।7

Email drjagdishrawat@yahoo.com
Background and objectives: Mechanical ventilation is the recommended treatment in unconscious patients with acute exacerbation of chronic obstructive pulmonary disease (COPD) and hypercapenic respiratory failure. But, in resource-poor countries, many of these patients are not able to afford this treatment due to financial constraints. The main aim of this study was to evaluate the usefulness, safety and cost-effectiveness of bilevel positive airway pressure (BiPAP) applied via endotracheal tube in such patients.

Methods: Twenty patients with acute exacerbation of COPD and altered sensorium, who were unable to afford ventilatory support, were intubated and BiPAP therapy was provided to these patients through the endotracheal tube. The outcome of these patients was studied.

Results: The BiPAP success rate and hospital mortality were $85 \%(17 / 20)$ and $15 \%(3 / 20)$ respectively. BiPAP failure was associated with high sequential organ failure assessment (SOFA) score at the time of admission $(P=0.002)$. Improvement in Glasgow coma scale (GCS) score $(P<0.001), \mathrm{pH}(P=0.001), \mathrm{PaCO}_{2}$ (partial pressure of carbon dioxide) $(P<0.001)$, respiratory rate $(P<0.001)$, and SOFA score $(P=0.001)$ was observed among the responders following 2 hours of therapy. Only one of the responders developed aspiration pneumonitis, as a complication. The daily cost of BiPAP therapy was 8.75 times lower than the average cost of mechanical ventilation.

Conclusion: This pilot study reveals that this treatment modality could be a safe, costeffective and efficacious method of treatment in unconscious patients with acute exacerbation of COPD.

Keywords: bilevel positive air way pressure, chronic obstructive pulmonary disease, hypercapenic respiratory failure

\section{Introduction}

Noninvasive positive pressure ventilation (NIPPV) is a safe and effective means of improving gas exchange in acute respiratory failure (ARF). ${ }^{1}$ There is level I evidence to suggest that in patients with acute exacerbation of chronic obstructive pulmonary disease (COPD) and hypercapnic respiratory failure, adding noninvasive ventilation to standard therapy decreases the need for endotracheal intubation and reduces mortality. ${ }^{2-12}$

The use of NIPPV to treat ARF is a treatment that is contraindicated in comatose patients because of the risk of aspiration. As a result, intubation and mechanical ventilation in the intensive care unit remain the only option for such a group of patients. In developing countries like India, health care costs of intensive care unit (ICU) stay and ventilator support is unaffordable for a large proportion of patients. 
Moreover, in vast stretches of the country such facilities are unavailable. This leaves the treating physician with limited therapeutic alternatives.

This work was undertaken to evaluate the effectiveness of treating such comatose patients suffering from acute exacerbation of COPD, who could not afford the cost of mechanical ventilation in an ICU, with bilevel positive airway pressure (BiPAP), connected to an endotracheal tube. This approach was prompted by a few previous studies demonstrating clinical improvement in patients with hypercapnic coma following treatment with NIPPV. ${ }^{13-15}$ In contrast to those studies, instead of a face mask, in this study BiPAP was applied through an endotracheal tube to enable the periodic suctioning of airway secretions to minimize the chances of pulmonary aspiration and subsequent pneumonia.

\section{Materials and methods}

This prospective observational study was carried out from January 2008 to December 2008 in the respiratory intermediate care unit of Himalayan Institute Hospital, Deheradun, India. This four-bedded unit functions under the direct supervision of qualified pulmonologists and is attended round the clock by a trained nurse and a dedicated chest therapist with training in BiPAP administration. The study was approved by the institutional ethics committee, and written informed consent was obtained from the nearest accompanying family member of each patient.

Consecutive COPD patients with hypercapnic acute respiratory failure (partial pressure of carbon dioxide $\left[\mathrm{PaCO}_{2}\right]>45 \mathrm{mmHg}$ and $\left.\mathrm{pH}<7.25\right)$, reduced level of consciousness (Glasgow coma scale $[\mathrm{GCS}]$ score $<8$ ), who were ineligible for NIPPV via facemask and were unable to afford the cost of ventilatory support in ICU, were recruited in the study. The following exclusion criteria were adopted for the study: (1) refusal of the patient's attendant to perform endotracheal intubation, (2) hypoglycemic patients, (3) patients with impaired consciousness due to accompanying comorbidities like neurogenic coma, drug-induced altered sensorium, (4) patients whose hypoxia could not be corrected within 30 minutes of administration of BiPAP.

These patients were intubated tracheally and connected with NIPPV (BiPAP ST, Respironics, Inc, Murrysville, PA) via T-tube. This connector tube had two ends, one for the endotracheal tube and the other for BiPAP, and two ports, one for expiration and the other for oxygen. To minimize the risk of pulmonary aspiration, patients were kept in a recumbent position with the head raised at $45^{\circ}$. A nasogastric tube was inserted in all patients. Electrocardiogram (ECG), blood oxygen saturation $\left(\mathrm{SpO}_{2}\right)$, and noninvasive blood pressure were monitored continuously. A chest therapist was advised to carry out chest and limb physiotherapy and continuous watch on vital parameters. The device used in this study had the following features: (1) inspiratory positive airway pressure (IPAP), 4-30 $\mathrm{cm} \mathrm{H}_{2} \mathrm{O} \pm 2.5 \mathrm{~cm} \mathrm{H}_{2} \mathrm{O}$; (2) expiratory

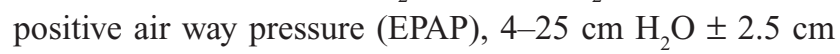
$\mathrm{H}_{2} \mathrm{O}$; (3) breath rate, $0-30$ breaths per minute; (4) timed inspiration, $0.5-3.0$ seconds $\pm 10 \%$ of the setting; (5) rise time, $1 \%-6 \% \pm 25 \%$; (6) ramp duration, $0-45$ minutes $\pm 10 \%$ of the setting. The device also had three alarm levels (high, medium, and low) depending on the extent of breathing circuit leakage and resulting apnea. The BiPAP was set in the spontaneous/ timed mode, with a backup respiratory rate of 15 breaths per minute. The initial IPAP was set at $14 \mathrm{~cm} \mathrm{H}_{2} \mathrm{O}$. IPAP was increased by $2-3 \mathrm{~cm} \mathrm{H}_{2} \mathrm{O}$ over 4 hours as tolerated but did not exceed $25 \mathrm{~cm} \mathrm{H}_{2} \mathrm{O}$. EPAP was begun at $4 \mathrm{~cm} \mathrm{H}_{2} \mathrm{O}$ and was increased up to $8 \mathrm{~cm} \mathrm{H}_{2} \mathrm{O}$, depending on the requirement of the patient. Oxygen inhalation was adjusted to maintain $\mathrm{SpO}_{2}$ between $89 \%$ and $92 \%$. Arterial blood gas (ABG) samples were obtained from each patient before and after 2 hours of initiation of BiPAP. Subsequently, samples were obtained every 24 hours or as clinically indicated.

The clinical course of the patient during the BiPAP therapy was monitored using GCS score, blood pressure, heart rate, respiratory rate, $\mathrm{ABG}$ levels, and sequential organ failure assessment (SOFA) score. Therapy was considered to have failed if at least one of the following occurred: (1) worsening of consciousness within 2 hours of initiating BiPAP; (2) deterioration of ABG, defined as no improvement or deterioration in $\mathrm{pH}, \mathrm{PaCO}_{2}$, and partial pressure arterial oxygen $\left(\mathrm{PaO}_{2}\right)$ /fraction of inspired oxygen $\left(\mathrm{FiO}_{2}\right)$ ratio from baseline measurement after 2 and 24 hours of BiPAP administration; (3) respiratory or cardiac arrest; and (4) development of hemodynamic instability. Treatment was considered successful when the patient gained full consciousness and was discharged alive from the hospital.

Short-acting benzodiazepines (midazolam) were advised as and when required in some patients who were restless and agitated. Patients were extubated once their consciousness increased enough to follow complex verbal command irrespective of $\mathrm{PaCo}_{2}$, and were thereafter applied with BiPAP via facemask.

\section{Statistical analysis}

Comparison of the monitored parameters between patients who improved and those who failed in the BiPAP therapy was done using Mann-Whitney $U$ test for quantitative variables and 
Fisher's exact test for qualitative variables. Progressive change with time in both the categories of patients was analyzed using the Wilcoxon signed rank test. Kaplan-Meier survival analysis was done using log-rank (Mantel-Cox) test. All analyses were two-tailed, and $P<0.05$ was considered significant. Statistical analysis was performed using SPSS Statistics (IBM Corporation, Somers, NY) software, version 16.0.

\section{Results}

During the study period, a total of 22 patients fulfilled the inclusion criteria for the study, attendants of four patients declined endotracheal intubation and left the hospital against medical advice. One patient's hypoxic status could not be corrected within 30 minutes with BiPAP administration and had to be shifted to bag valve mask (Ambu bag) resuscitation. Of the 22 patients recruited in the study, two patients were shifted to ICU during the course of BiPAP therapy owing to the subsequent availability of funds, and hence they were excluded from the final analysis. Out of the remaining 20 patients, 17 responded successfully to the treatment and three failed to respond and died.

The baseline characteristics and physiological variables of these patients were comparable in almost all respects, as shown in Table 1. However, the SOFA score of the successfully treated patients was significantly better than in the nonresponders $(P=0.004)$.

Analyzing the progressive course of the treated patients, a significant improvement in all the monitored parameters was observed among the favorable responders by the end of the second hour of treatment. However, the systolic blood pressure remained unchanged at the end of 2 hours. Among the nonresponders, no change was observed in any of the monitored parameters at the end of 2 hours. The positive change in all the parameters observed among the responders at the end of 2 hours was maintained throughout the duration of treatment (Table 2).

Among the patients who responded to the treatment, only one patient developed lobar pneumonia of the right lower lobe, which could be attributed to aspiration pneumonia. It resolved on administration of piperacillin-tazobactam for 8 days. No other complication associated with BiPAP therapy was observed in any other patient.

Maximum inspiratory pressure applied during BiPAP therapy was similar between the responders and nonresponders [median (range) for responders and nonresponders being 17.5 (16.7-19.6) and 18.2 (17.9-19.5) respectively; $P=0.379]$. The time of administering BiPAP therapy was also comparable between the two groups [median (range) for responders and nonresponders being 3.8 (2.7-5.0) and $3.0(2.0-4.0)$ respectively; $P=0.469$ ]. The three patients who failed on this treatment died on the second, third, and fourth days of hospitalization, while the median (range) time of hospitalization among the responders was 8 (5-15) days. Follow-up until the 14th day showed a significant difference in survival between the responders and nonresponders ( $P \leq 0.001$; log-rank [Mantel-Cox] test).

Comparing the financial implications of BiPAP therapy and mechanical ventilation, the average charges for the former was calculated to be INR 2800 (US\$62.10) per patient. This was based on a daily charge of INR 800 (US\$17.74) levied by the hospital for administering BiPAP therapy. The corresponding daily cost for mechanical ventilation, apart from ICU charges, is INR 7000 (US\$155.24), and hence, a similar duration of mechanical ventilation would have resulted in an average cost of INR 24,500 (US\$543.34), which is 8.75 times higher than the average cost of BiPAP therapy.

Table I Patient characteristics of two group and baseline physiological variables in COPD patients with coma

\begin{tabular}{llll}
\hline Variable & Median (range) & & P-value \\
\cline { 2 - 3 } & Responders $(\mathbf{n}=17)$ & Nonresponders $(\mathbf{n}=\mathbf{3})$ \\
\hline Age (years) & $60(38-72)$ & $60(55-65)$ & 0.957 \\
Gender distribution (M/F) & $15 / 2$ & $2 / 1$ & 0.404 \\
COPD duration (years) & $10(2-14)$ & $12(10-20)$ & 0.199 \\
Smoking (pack years) & $10(2-14)$ & $18(0-20)$ & 0.264 \\
GCS & $6(3-7)$ & $14-7)$ & 0.438 \\
Systolic blood pressure & $122(90-150)$ & $132(102-122)$ & 0.111 \\
Heart rate (beats/min) & $116(90-136)$ & $32(28-34)$ & 0.022 \\
Respiratory rate (breaths/min) & $28(22-36)$ & 7.1 & 0.145 \\
PH & $7.1(6.9-7.2)$ & $32(28-34)$ & 0.872 \\
PaCO & $28(22-36)$ & $7(7-8)$ & 0.559 \\
SOFA score & $3(2-5)$ & 0.004 \\
\hline
\end{tabular}

Abbreviations: COPD, chronic obstructive pulmonary disease; $\mathrm{F}$, female; GCS, Glasgow coma scale; $\mathrm{M}$, male; PaCO, partial pressure of carbon dioxide; SOFA, sequential organ failure assessment. 
Table 2 Comparison of vital signs and ABG variables with length of BiPAP administration between two groups

\begin{tabular}{|c|c|c|c|c|c|}
\hline Variable & Baseline & At 2 hours & $\begin{array}{l}\text { P-value } \\
\text { (within the group) }\end{array}$ & At end ${ }^{a}$ & $\begin{array}{l}\text { P-value } \\
\text { (within the group) }\end{array}$ \\
\hline \multicolumn{6}{|l|}{ Systolic BP } \\
\hline Responder $(n=17)$ & $122 \pm 15.9$ & $117 \pm 9.1$ & 0.177 & $114 \pm 11.2$ & 0.039 \\
\hline Nonresponder $(n=3)$ & $104 \pm 16.0$ & $102 \pm 7.2$ & 0.102 & $104 \pm 14.4$ & 1.000 \\
\hline \multicolumn{6}{|l|}{ Heart rate } \\
\hline Responder $(n=17)$ & $113 \pm 16.0$ & $101 \pm 11.4$ & 0.001 & $86.7 \pm 4.5$ & 0.003 \\
\hline Nonresponder $(n=3)$ & $120 \pm 22.2$ & $119 \pm 20.4$ & 0.593 & $123 \pm 23.3$ & 0.109 \\
\hline \multicolumn{6}{|l|}{ Respiratory rate } \\
\hline Responder $(n=17)$ & $28.3 \pm 3.8$ & $23.3 \pm 3.5$ & $<0.001$ & $18.3 \pm 2.6$ & $<0.001$ \\
\hline Nonresponder $(n=3)$ & $29.3 \pm 2.3$ & $30 \pm 3.4$ & 0.902 & $30.6 \pm 5.7$ & 0.593 \\
\hline \multicolumn{6}{|l|}{ pH } \\
\hline Responder $(n=17)$ & $7.01 \pm 0.09$ & $7.12 \pm 0.07$ & 0.001 & $7.31 \pm 0.04$ & $<0.001$ \\
\hline Nonresponder $(n=3)$ & $7.1 \pm 1.09$ & $7.11 \pm 1.0$ & 1.000 & $7.08 \pm 0.15$ & 0.420 \\
\hline \multicolumn{6}{|l|}{$\mathrm{PaCO}_{2}$} \\
\hline Responder $(n=17)$ & $97.1 \pm 14.3$ & $78 \pm 12.3$ & $<0.00$ I & $55.5 \pm 5.9$ & $<0.00$ I \\
\hline Nonresponder $(n=3)$ & $93.6 \pm 4.0$ & $95.3 \pm 10.5$ & 1.000 & $106 \pm 7.2$ & 0.109 \\
\hline \multicolumn{6}{|l|}{ SOFA score } \\
\hline Responder $(n=17)$ & $5.2 \pm 0.7$ & $3.2 \pm 0.3$ & 0.001 & $0.35 \pm 0.6$ & $<0.00$ I \\
\hline Nonresponder $(n=3)$ & $7.3 \pm 0.5$ & $6.6 \pm 0.2$ & 0.626 & $6.0 \pm 1.0$ & 0.105 \\
\hline \multicolumn{6}{|l|}{ GCS } \\
\hline Responder $(n=17)$ & $5.8 \pm 1.0$ & $10.5 \pm 1.7$ & $<0.001$ & $14.6 \pm 2.6$ & $<0.00 \mathrm{I}$ \\
\hline Non-responder $(n=3)$ & $6.3 \pm 1.1$ & $7.0 \pm 1.7$ & 0.157 & $4.3 \pm 0.5$ & 0.109 \\
\hline
\end{tabular}

Note: "At end" signifies the termination of BiPAP therapy.

Abbreviations: ABG, arterial blood gas; BiPAP, bilevel positive airway pressure; BP, blood pressure; GCS, Glasgow coma scale; $\mathrm{PaCO}_{2}$, partial pressure of carbon dioxide; SOFA, sequential organ failure assessment.

\section{Discussion}

Reported in this study, is the favorable outcome and cost-effectiveness of BiPAP therapy, administered through an endotracheal tube, in COPD patients with acute type II respiratory failure and reduced level of consciousness. Also demonstrated is that reduced SOFA scores at initiation of treatment carries a better prognosis for this modality of treatment. To the best of the authors' knowledge, this is the first study showing the potential utility of this therapy in these situations.

Owing to the risk of aspiration, NIPPV is hardly considered as a therapeutic option in patients of acute respiratory failure with impaired consciousness, and this probably explains the paucity of literature on the subject. ${ }^{13-18}$ Among the limited number of studies in this area, the one reported by Scala et $a{ }^{13}$ demonstrated better outcome of NIPPV in patients with improved level of consciousness. In their study, success rates of $85 \%, 75 \%$, and $55 \%$ was observed in patients with Kelly scores of 1, 2, and 3 respectively. ${ }^{10}$ However, comparing the response to NIPPV between COPD patients with a GCS score of $\geq 8$ and those with a score below 8 , Diaz and coworkers have recently reported similar success rates (defined as avoidance of endotracheal intubation and survival for 24 hours after discharge from ICU) and hospital mortality rates in the two groups. ${ }^{14}$ Zhu et a ${ }^{15}$ have also reported successful treatment with NIPPV in 11 of 13 comatose patients. In another study conducted on 30 patients, three patients were comatose, of which two were successfully treated with NIPPV. ${ }^{16}$ In comparison with these studies, a different methodology was adopted for administering BiPAP therapy in this study. Instead of BiPAP being applied via face mask, an endotracheal tube was used for administration, and a better success rate and lower mortality was observed compared with the previous studies. The better outcome could be due to reduction of the chances of aspiration and subsequent pneumonia or sepsis following the application of an endotracheal tube. Moreover, administration of this therapy through endotracheal tube allows for more effective delivery of inspiratory pressure to the airways and minimizes the chances of leakage of the same through potential air spaces underneath an ill-fitting face mask. Isolated case reports have also described successful application of NIPPV in selected patients with hypercapnic coma. ${ }^{17,18}$

Certain precautions were taken before using the BiPAP ST device for an off-label application. Firstly, to avoid power failures, the device was used only under the back-up of uninterrupted power supply (UPS). Secondly, the on-site availability of a trained respiratory therapist was ensured around the clock in order to recognize and respond to any untoward complication arising during the course of the therapy. A maximum $\mathrm{FiO}_{2}$ of $45 \%-50 \%$ can be delivered with this device, which can impair its utility in certain cases, and accordingly the decision 
was made to give a trial of 30 minutes with this device and then to shift the patient to bag valve mask (Ambu bag) resuscitation if the hypoxic state did not get corrected.

Apart from the modification in the method of administering BiPAP, several important revelations emerged from this pilot study. Firstly, SOFA score was found to be significantly different between the responders and the nonresponders, which probably implies poor prognosis of this treatment modality in COPD patients with multisystem involvement. Secondly, in all responders, positive response was observed quite early in the treatment, ie, by 2 hours of initiating BiPAP therapy, while non responders showed progressive deterioration in all the parameters monitored at this time-point. This suggests that potential responders can be identified relatively early in course of treatment and the nonresponders can be considered for ventilator therapy at the end of 2 hours. Thirdly, the mean duration of BiPAP therapy was 3.6 days among the responders, while the mean duration of hospitalization was 8.4 days. This suggests that these patients could be successfully weaned from NIPPV therapy and did not require any respiratory support over a significant duration of hospital stay subsequent to this therapy.

Although this study was conducted on a small sample size, which included only three nonresponders, the promising results obtained by us merit further validation in a more elaborate randomized trial, and the results of BiPAP therapy need to be compared with the outcome of ventilator therapy. In the event of these initial findings being authenticated, this treatment modality can offer a valuable alternative to the more expensive and technically demanding ventilator therapy, particularly in resource-constrained situations. However, it would be apt to use a suitable and safe device for this purpose that can deliver adequate inspiratory and expiratory pressure through an endotracheal tube, possess satisfactory power back-up, and provide alarm signals in case of emergency. Hybrid ventilators, which perform both pressure and volume preset ventilation and are substantially cheaper than an ICU ventilator, could be an appropriate alternative in this regard.

\section{Disclosure}

The authors report no conflicts of interest in this work.

International Journal of COPD

\section{Publish your work in this journal}

The International Journal of COPD is an international, peer-reviewed journal of therapeutics and pharmacology focusing on concise rapid reporting of clinical studies and reviews in COPD. Special focus is given to the pathophysiological processes underlying the disease, intervention programs, patient focused education, and self management protocols.

\section{References}

1. Ram FS, Picot J, Lightowler J, et al. Noninvasive positive pressure ventilation for treatment of respiratory failure due to exacerbations of chronic obstructive pulmonary disease. Cochrane Database Syst Rev. 2004;3:CD004104.

2. Meduri GU. Noninvasive positive-pressure ventilation in patients with acute respiratory failure. Clin Chest Med. 1996;17:513-553.

3. Bersten AD, Holt AW, Vedig AE, et al. Treatment of severe cardiogenic pulmonary edema with continuous positive airway pressure delivered by face mask. N Engl J Med. 1991;325:1825-1830.

4. Bott J, Carroll MP, Conway JH, et al. Randomised controlled trial of nasal ventilation in acute ventilatory failure due to chronic obstructive airways disease. Lancet. 1993;341:1555-1557.

5. Rasanen J, Heikkila J, Downs J, et al. Continuous positive airway pressure by face mask in acute cardiogenic pulmonary edema. Am J Cardiol. 1985;55:296-300.

6. Ahmed AH, Fenwick L, Angus RM, et al. Doxapram in the treatment of type II respiratory failure complicating chronic airflow obstruction. Thorax. 1992;1:858.

7. Meduri GU, Turner RE, Abou-Shala N, et al. Noninvasive positive pressure ventilation via face mask: first-line intervention in patients with acute hypercapnic and hypoxemic respiratory failure. Chest. 1996;109:179-193.

8. Daskalopoulou E, Tsara V, Fekete K, et al. Treatment of acute respiratory failure in COPD patients with positive airway pressure via nasal mask (NPPV). Chest. 1993;103 Suppl:271S.

9. Keenan SP, Kernerman PD, Cook DJ, et al. The effect of noninvasive positive pressure ventilation on mortality in patients admitted with acute respiratory failure: a meta-analysis. Crit Care Med. 1997;25:1685-1692.

10. Tamanna S, Ullah MI. Use of noninvasive ventilation in general ward for the treatment of respiratory failure. J Miss State Med Assoc. 2011;52:278-281.

11. Cabrini L, Antonelli M, Savoia G, et al. Non-invasive ventilation outside of the intensive care unit: an Italian survey. Minerva Anestesiol. 2011;77:313-322.

12. Cabrini L, Monti G, Pischedda A, et al. Non-invasive ventilation outside intensive care unit for acute respiratory failure: the perspective of a general ward nurse. Minerva Anestesiol. 2009;75:427-433.

13. Scala R, Naldi M, Archinucci I, et al. Noninvasive positive pressure ventilation in patients with acute exacerbations of COPD and varying levels of consciousness. Chest. 2005;128:1657-1666.

14. Diaz GG, Alcaraz AC, Talavera JC, et al. Noninvasive positive-pressure ventilation to treat hypercapnic coma secondary to respiratory failure. Chest. 2005; 127:952-960.

15. Zhu L, Niu SF, Li YQ, et al. Effectiveness of mechanical ventilation via face mask on comatose patients with chronic obstructive pulmonary disease induced respiratory failure. Chin Crit Care Med. 1997;9:28-30.

16. Benhamou D, Girault C, Faure C, et al. Nasal mask ventilation in acute respiratory failure: experience in elderly patients. Chest. 1992;102: 912-917.

17. Scala R, Archinucci I, Naldi, et al. Noninvasive nasal ventilation in a case of hypercapnic coma. Minerva Anestesiol. 1997;63:245-248.

18. Adnet F, Racine SX, Lapostolle F, et al. Full reversal of hypercapnic coma by noninvasive positive pressure ventilation. Am J Emerg Med. 2001;19:244-246.

\section{Dovepress}

This journal is indexed on PubMed Central, MedLine and CAS. The manuscript management system is completely online and includes a very quick and fair peer-review system, which is all easy to use. Visit http://www.dovepress.com/testimonials.php to read real quotes from published authors. 